\title{
DIPLOMACIA, LINAJE Y POLIITICA DURANTE LA CRISIS DE LAS MONARQUÍAS IBÉRICAS. DISPUTAS EN TORNO A LA CANDIDATURA DE CARLOTA JOAQUINA DE BORBÓN ENTRE 1808 Y 1810
}

Diplomacy, lineage and politics during the crisis of the Iberian monarchies. Disputes about the candidacy of Carlota Joaquina de Borbón between 1808 and 1810

\author{
MARCELA TERNAVASIO \\ Universidad Nacional de Rosario. IECH CONICET/UNR \\ marcelaternavasio@gmail.com

El presente artículo se propone examinar algunos aspectos del debate que, en el marco de la crisis de la monarquía española producida en 1808, encarnó la infanta Carlota Joaquina de Borbón. A través de las redes diplomáticas tejidas a escala interimperial se busca iluminar las opciones y representaciones que se fueron configurando entre 1808 y 1810 al presentarse una alternativa de regencia para cubrir provisionalmente la vacatio regis. Las redes de vínculos y conflictos que exhibe el denso corpus documental revelan dos cuestiones centrales que atraviesan los argumentos de las siguientes páginas: la primera es el papel que jugó la lógica del linaje dinástico para enfrentar las tendencias constitucionalistas que, bajo diversos formatos, se presentaron en el mundo ibérico frente al avance napoleónico; la segunda 
contempla las amenazas que esa misma lógica desató en distintos frentes a nivel internacional al poner en juego la potencial unidad de las dos coronas ibéricas y la potencial americanización de la monarquía española.

\title{
Palabras clave
}

Carlota Joaquina; diplomacia; linaje; política.

\begin{abstract}
In the context of the crisis of the Spanish monarchy generated in 1808, this article intends to examine some aspects of the debate that took place around the figure of infanta Carlota Joaquina de Borbón. Through the diplomatic networks woven in an interimperial scale, it seeks to illuminate the options and representations that were configured between 1808 and 1810 when an alternative regency was presented to provisionally cover the vacatio regis. The network of links and conflicts exhibited by the dense documentary corpus reveal two central questions that cross the arguments of the following pages. The first is the role played by the dynastic lineage logic to confront constitutional tendencies that, under different formats, appeared in the Iberian world before the Napoleonic advance. The second considers the threats that this same logic unleashed on different fronts at an international level by putting into play the potential unity of the two Iberian crowns and the potential Americanization of the Spanish monarchy.
\end{abstract}

\section{Keywords}

Carlota Joaquina; diplomacy; lineage; politics. 


\section{SUMARIO}

I. INTRODUCCIÓN. II. DINASTISMO, GEOPOLÍTICA Y GÉNERO. III. DOS PROPUESTAS DE REGENCIA. IV. LA DIPLOMACIA EN ACCIÓN. V. LA DIPLOMACIA ESPAÑOLA DESDOBLADA. VI. EL LINAJE DINÁSTICO EN SUSPENSO. BIBLIOGRAFIA.

\section{INTRODUCCIÓN'}

En mayo de 1808, cuando se produjeron los episodios de Bayona, nada hacía presumir que poco más de dos años después se reuniría una Asamblea Constituyente en la que sus diputados jurarían en nombre de un nuevo sujeto de imputación soberana: la nación española. Durante ese tormentoso bienio, las disputas en torno al depósito de la soberanía vacante, que de hecho asumieron las juntas locales y luego la Junta Suprema Central, exhibieron la posibilidad de buscar una salida dinástica a través de una regencia encarnada por un miembro de la familia real. La propuesta de designar a Carlota Joaquina de Borbón a la cabeza de dicha regencia fue, sin dudas, la que más revuelo provocó.

A pesar de que gran parte de la historiografía la consideró por mucho tiempo como una respuesta extravagante que no podía sino fracasar, no parece una opción descabellada si se la contempla desde la coyuntura en la que fue promovida. Además de prometer la defensa del orden vigente, se proponía neutralizar la amenaza de una deriva revolucionaria, garantizar la unidad monárquica e imperial y evitar la federalización que, de hecho, se produjo en el orbe hispano. Pero, como sabemos, esa alternativa no se impuso por varias razones. El éxito inicial de las juntas que ignoraron al rey impuesto por Napoleón Bonaparte y que asumieron la iniciativa política y bélica contra Francia, el clima de profunda exaltación patriótica que experimentó España, el desprestigio de las principales magistraturas que aceptaron las abdicaciones, la formación de la Junta Central que procuró unificar el depósito de la soberanía fragmentado entre las juntas locales, y la creciente convicción de que la crisis tenía un carácter constitucional que exigía la convocatoria a Cortes explican en gran parte el fracaso de una respuesta dinástica a la vacatio regis.

Sin embargo, la frustración de los planes carlotistas no se explica solamente por la correlación de fuerzas internas en el mundo hispano, sino por

Agradezco a José María Portillo Valdés su atenta lectura a una versión preliminar de este artículo y sus oportunas y agudas sugerencias para mejorarlo. 
el entrelazamiento de dichas fuerzas con las procedentes de otras potencias. La infanta española, hermana mayor de Fernando VII y esposa del príncipe regente de Portugal, João de Braganza, se coinvirtió en aquellos convulsionados ańos en una figura clave. Promovida por la corte portuguesa, por algunos personajes de significativo peso político en Espańa asociados a los grupos más conservadores e incluso moderados, y por la propia vocación de poder que la princesa demostró tener en todas las etapas de su vida, su postulación desató intensos debates en el escenario peninsular y americano, así como entre las diferentes potencias involucradas en el conflicto internacional abierto por el avance del emperador francés sobre las monarquías ibéricas.

Las complejas redes de relaciones, disputas y negociaciones que desnudan las gestiones de los ministros plenipotenciarios que actuaron en ese momento, abren un campo de reflexión en torno al papel que jugó el principio dinástico en el agitado clima político producido por el traslado de la corte portuguesa a Brasil y la vacante de la Corona en Espańa. En ese campo de reflexión se instala el presente artículo, cuyo propósito es examinar algunos aspectos del debate en torno a la alternativa encarnada por la infanta Carlota Joaquina de Borbón entre 1808 y 1810 con el fin de iluminar, a través de las redes diplomáticas, las opciones y representaciones que se fueron configurando al presentarse una iniciativa que buscaba enfrentar la amenaza revolucionaria y constitucionalista a través del principio de linaje y sucesión dinástica.

El punto de llegada de esta periodización coincide con el momento en el que se concretó la salida constituyente gaditana, cuando los planes carlotistas debieron adaptarse al nuevo escenario creado por las Cortes; un escenario que habilitó la posibilidad de constitucionalizar los derechos sucesorios de la infanta y que merece un tratamiento aparte, imposible de abordar en el marco de este artículo ${ }^{2}$. No obstante, el recorte cronológico seleccionado se funda en la convicción de que para poder comprender cabalmente todo lo que se jugó en dichas Cortes al momento de debatir la ley de sucesión es preciso ahondar en algunas de las tramas que se fueron tejiendo en el bienio precedente a escala interimperial y, sobre todo, iberoamericana.

Si bien se trata de un tema transitado por algunos especialistas, su tratamiento dentro del campo de la historia política ha seguido, por lo general, caminos paralelos por parte de las historiografías nacionales, más atentas

2 El tratamiento de los derechos sucesorios de la infanta Carlota en las Cortes de Cádiz está desarrollado en un libro de mi autoría y en un artículo aún inédito en el que exploro en mayor profundidad el tema. Véase al respecto Ternavasio (2015). 
durante mucho tiempo a los avatares de fuerzas políticas e ideológicas internas que a las relaciones de poder construidas a través de vínculos relacionales expresados en amplias y diferentes geografías ${ }^{3}$. En este sentido, el presente estudio se inscribe en las perspectivas que bajo diversas denominaciones - historias conectadas, cruzadas, transnacionales, globales - problematizan la cuestión de las escalas de análisis, sin asumir la pretensión de discutir acerca de las perspectivas que distinguen a cada uno de estos enfoques ${ }^{4}$. Por el contrario, lo que interesa destacar es que el objeto de análisis aquí tratado nos ubica necesariamente en un contexto que trasciende las fronteras locales y que a su vez sigue la pista de una trayectoria individual que, en este caso, gira en torno a la figura de la infanta española y princesa portuguesa. Como sabemos, el principio de linaje dinástico traspasaba los límites territoriales en los que las monarquías ejercían sus potestades, al estar emparentadas sus casas soberanas a través de estrategias matrimoniales que ponían el acento en los vínculos de sangre para entablar negociaciones políticas entre las familias reinantes.

En el contexto creado en 1808, el carácter imperial de las dos monarquías ibéricas y el parentesco dinástico que las unía desde la celebración de los contratos matrimoniales de 1785 — cuando durante el reinado de Carlos III se buscó acercar las dos coronas a través de un doble casamiento entre dos infantes españoles y dos infantes portugueses - ${ }^{5}$ dejó abierto un debate que descubre la intrincada relación entre el campo de la diplomacia y el campo de la política, en una coyuntura en la que los principios que regulaban ambos campos habían comenzado a sufrir una profunda transformación. Las redes de vínculos y conflictos que exhibe el denso corpus documental revelan dos cuestiones centrales que atraviesan los argumentos de las siguientes páginas: la primera es el papel que jugó la lógica del linaje dinástico para enfrentar las tendencias constitucionalistas que, bajo diversos formatos, se presentaron en el mundo ibérico frente al avance napoleónico; la segunda contempla las amenazas que esa misma lógica desató en distintos frentes a nivel internacional al

3 Cabe destacar la importancia de dos obras pioneras sobre el tema que nos ocupa: Lima (2006) y Rubio (1920). Entre las obras más recientes que exploran la alternativa dinástica de Carlota Joaquina véanse: Marques Pereira (1999); Nogueira de Azevedo (2002, 2008); Pimenta (2011); Martiré (2006, 2008); Costa (2013); López Cordón (2009, 2014); Brancato (2003), y Palacio (2008).

4 Para un estado del debate sobre estos enfoques véanse: Werner y Zimmermann (2006); Struck et al. (2011), y Serulnikov y Lluch (2014).

5 Los contratos matrimoniales de 1785 concertaron el doble casamiento de Gabriel de Borbón (hermano del futuro Carlos IV) con la infanta Mariana Victoria de Portugal y el de Carlota Joaquina de Borbón con el príncipe João de Braganza. 
poner en juego la potencial unidad de las dos coronas ibéricas y la potencial americanización de la monarquía española ${ }^{6}$.

\section{DINASTISMO, GEOPOLIITICA Y GÉNERO}

La ocupación francesa de la península ibérica entre 1807 y 1808 provocó dos hechos extraordinarios: el traslado de la familia real y de toda la corte lusitana a Brasil y las renuncias de los reyes espańoles en la ciudad de Bayona. Cuando Napoleón Bonaparte puso en jaque la supervivencia de las dos casas reinantes en la península, las diferentes reacciones de los Braganza y de los Borbones trazaron trayectorias distintas. La ausencia real derivó en Portugal en una profunda crisis política cuyo principal escenario estuvo en la península, mientras que en España tuvo lugar una crisis constitucional de la monarquía que afectó por igual a todo el imperio7.

La imagen consagrada por Ernst Kantorowicz (2012) en su estudio sobre Los dos Cuerpos del Rey, en el que analiza la ficción mística en la que se apoyó la monarquía inglesa, es útil para ilustrar el dilema que experimentó España y que supo evitar Portugal en esa coyuntura crucial ${ }^{8}$. La monarquía lusa pudo mantener unidos el cuerpo físico del rey y el cuerpo político e inmaterial de la Corona a través del mítico viaje emprendido a través del Atlántico. La Corona quedaba así a salvo, desplazándose junto con su titular y todo el funcionariado desde Lisboa a Río de Janeiro, y pudo de ese modo fungir como cabeza de la unidad soberana y de la obligación política de todo el imperio. En la

6 El corpus documental utilizado fue extraído de los siguientes archivos: Archivo General de Palacio Real, Madrid (AGP); Archivo General de Indias, Sevilla (AGI); Archivo Histórico Nacional, Madrid (AHN); Biblioteca Nacional, Madrid (BN); Archivo Histórico Museo Imperial, Petrópolis (AHMI); Archivo del Ministerio de Relaciones Exteriores, Itamaraty (AMRE); Foreign Office Archives (FOA); Archivo General de la Nación de Buenos Aires (AGN); Mayo Documental, Universidad de Buenos Aires, Facultad de Filosofía y Letras, 1962 (MD).

7 Sobre el carácter extraordinario de ambas crisis, véanse — entre muchos otros trabajos - para el caso portugués: Alexandre (1993); Ramos (2008); Schultz (2001); Moritz Schwarcz (2008); Slemian (2009), y Slemian y Pimenta (2008). Para el caso hispano: Annino (2008); Ávila y Herrero (2008); Breña (2006, 2010); Chust (2007); Garriga (2010); Lorente y Portillo Valdés (2012), y Portillo Valdés (2000, 2006). Para una perspectiva comparada luso-hispana: Adelman (2007); Annino y Ternavasio (2012); Halperin Donghi (1985); Pimenta (2011), y Varela Suanzes-Carpegna (2007).

8 Kantorowicz (2012). 
monarquía española, en cambio, el cuerpo físico del rey se hallaba en territorio extranjero, donde había entregado el cuerpo político a un monarca que no pertenecía al linaje dinástico borbónico. El principio de linaje era desde el medievo la garantía de perpetuidad de una dinastía y el reaseguro para que el carácter político y corporativo de la Corona no sufriera los peligrosos interregnos que implicaba la muerte de un monarca. De hecho, España había experimentado un interregno complicado cuando a la muerte sin descendencia de Carlos II de Habsburgo le sucedió la guerra de Sucesión y el cambio de dinastía a comienzos del siglo XviII. Pero esa muerte física del rey no puso en jaque a la Corona ni al imperio; en todo caso dejó abierto el conflicto para que los linajes de las casas soberanas europeas emparentadas con los Habsburgo disputaran a través de las armas sus derechos sobre el trono español. El dilema de 1808 era que el cuerpo físico del rey no había muerto, sino abdicado voluntaria e ilegalmente el cuerpo político de la Corona en las célebres transmisiones de Bayona que recayeron en José Bonaparte. El nuevo monarca era una pieza más de la estrategia napoleónica que procuraba asentar a los Bonaparte como casa imperial de Francia, regando Europa de príncipes dependientes de dicha casa. Pero ese intento de consolidar una dinastía bonapartista en el Viejo Mundo carecía de un elemento fundamental: la tradición que exhibían las casas reinantes. Quedaba así abierto en el mundo hispano el gran problema de la soberanía.

En esas trayectorias diversas hubo, sin embargo, íntimas conexiones. La proximidad territorial, los antecedentes de unión de las dos coronas, el repentino cambio de alianzas internacionales y la lucha compartida contra los franceses explican en gran parte tales conexiones. Pero españoles y portugueses enfrentaron, además, un desafío común: ¿cómo salvar e imaginar el futuro de sus monarquías frente a las respectivas crisis que experimentaban y ante el avance revolucionario que, desde fines del siglo XviII, venía trastocando el orbe Atlántico? La cuestión dinástica está pues en la base de algunas de las respuestas ofrecidas a este interrogante, cuyo impacto en la situación creada en 1808 debe medirse en función de las transformaciones y tensiones que se fueron configurando a lo largo del siglo XviII. Sobre tres aspectos fundamentales de esas transformaciones nos detendremos brevemente para encuadrar el problema que aquí nos ocupa: el primero refiere a la tensión entre dinastismo e intereses geopolíticos; el segundo a la amenaza del nuevo constitucionalismo frente a las leyes fundamentales de las monarquías ibéricas, y el tercero al estatus político y jurídico de las mujeres en las monarquías reinantes.

Respecto de la primera dimensión es preciso recordar lo que destacan los renovados estudios sobre el siglo XVIII: los tratados de Utrecht (1713-1715), que pusieron fin a la guerra de Sucesión española y reconocieron a la nueva 
dinastía borbónica, implicaron el pasaje de una lógica europea fundada en las casas soberanas (y por lo tanto en el principio dinástico, en la primacía de un linaje y en las estrategias matrimoniales para encarnar negociaciones políticas) a una lógica que privilegiaba las relaciones de fuerza entre potencias 9 . Desde entonces, la lógica dinástica debió coexistir con una nueva noción de equilibrio para regular la competencia entre potencias por razones geopolíticas y económicas, por un lado, y con el creciente papel que asumió la noción de patriotismo y de interés nacional en el seno de las monarquías, por el otro ${ }^{10}$. En ese contexto, el cambio de las alianzas internacionales que provocó la ocupación napoleónica de la península ibérica venía a trastocar el tablero de posiciones en el que se habían movido las potencias durante el siglo xviII. La reacción juntista española que no reconoció al nuevo rey impuesto por el emperador galo implicó que Francia pasara de ser aliada a enemiga de España y que esta última, a partir de allí, tuviera como principales socias a sus tradicionales adversarias: Inglaterra y Portugal.

La tensión entre dinastismo e intereses geopolíticos encontró un nuevo escenario para desplegarse en los derroteros que siguieron las dos monarquías ibéricas frente a los hechos extraordinarios de 1808, cuando se reactualizó el segundo aspecto mencionado: la cuestión constitucional. Al clima de cuño ilustrado en el que se habían nutrido parte de las elites españolas y portuguesas en el último cuarto del siglo Xvin, y que dejaba planteado el debate en torno a reformar las monarquías, se sumó el avance constitucionalista de Napoleón, dispuesto a mediatizar las monarquías europeas ${ }^{11}$. La sanción de la Carta de Bayona para Espańa, apoyada por los afrancesados hispanos, se dio en un contexto en el que algunas élites ilustradas y liberales lusas buscaron aprovechar la huída de la familia real para proponerle al emperador de Francia que diera a Portugal una constitución y un rey constitucional con un príncipe de sangre de la familia Bonaparte, o promover al general Junot al mando de las tropas allí acantonadas como futuro rey ${ }^{12}$.

Ambas iniciativas, que expresan el modo en que Napoleón buscaba consolidar la nueva casa dinástica de los Bonaparte constitucionalizando su imperio, quedaron frustradas en la península ibérica con resultados diferentes. En el caso español, la reacción juntista no reconoció al nuevo monarca constitucionalizado en Bayona para dar lugar a un proceso que culminó en la convocatoria de una Asamblea Constituyente de la nación espańola; y en Portugal,

\footnotetext{
Bély (2002) y Ozanam (2002).

Lorente y Portillo Valdés (2012).

Portillo Valdés (2010).

12 Araújo (1998) y Ramos (2008).
} 
la reacción juntista surgida en Oporto y extendida luego a otras ciudades para oponerse a los invasores, tuvo carácter efímero ${ }^{13}$. El desembarco del ejército británico terminó de abortar las pretensiones de Francia y de los afrancesados sobre la metrópoli lusa, como asimismo del movimiento juntista portugués que tanta alarma había despertado en la corte de Braganza. Pero lo que dejaban como legado ambas experiencias era la amenaza concreta que, dentro de sus respectivos territorios, vivían las casas soberanas ibéricas que hasta allí habían intentado mantener el orden absolutista. Para la familia real portuguesa, alejada del escenario europeo, era fundamental aceitar las redes diplomáticas para hacer frente a dicha amenaza en nombre de la «antigua constitución». Y para el mundo hispano se abrían — según destacan Lorente y Portillo Valdés (2012) — profundas divergencias sobre el concepto de «constitución». El bienio 1808-1810 fue, en este sentido, una cantera de diferencias y la más notable, según los autores citados, tuvo que ver con la cuestión sobre si la monarquía o sus partes tenían una constitución y sobre la necesidad u oportunidad en aquellos momentos de «formarla, restablecerla, o asegurar su observancia» ${ }^{14}$.

El debate en torno a la cuestión constitucional se vincula al tercer aspecto de las transformaciones antes señaladas, y que atañe al papel político y jurídico de las mujeres pertenecientes a las casas soberanas. Se trata de un tema que ha merecido una especial atención de los estudiosos. La reciente producción historiográfica sobre la acción de reinas, princesas y regentes en las monarquías de la época moderna destacan los cambios ocurridos cuando comenzaron a asumir nuevos roles en las esferas de poder. Como sabemos, el casamiento regio era una materia de Estado y una alianza entre dinastías; garantizar el linaje y la sucesión dinástica era, por cierto, el objetivo central que las mujeres tenían dentro del casamiento regio para evitar la ascendencia de ramas colaterales ${ }^{15}$. Pero, como destacan Gutiérrez et al. (2014: 14), a las funciones tradicionales de las reinas como núcleo sustentador de la familia real en pos de perpetuar la dinastía como esposas y madres de reyes, o en la posición de gobierno como regentes o reinas titulares, se fueron sumando otras como las de aprovechar los resortes de poder que les daba su vinculación al trono para influir e, incluso, liderar redes y acciones políticas con fuerte incidencia en las decisiones de las casas soberanas. Tales acciones, además de revelar los rasgos de mujeres poderosas y con autonomía de gestión, muchas veces producían desconcierto y

13 Sobre el debate en torno a la comparación de los movimientos juntistas luso e hispano, véanse: Costa (2013); Araújo (1998), y Ramos (2008).

14 Lorente y Portillo Valdés (2012): 70-71.

15 Marçal Lorenço (2012). 
serias resistencias entre los poderes involucrados por la propia condición femenina de quienes las encarnaban. Las reinas, princesas o regentes quedaron así sujetas a los discursos de género subyacentes en los diversos momentos que atravesaban las monarquías y su condición excepcional procedente del linaje no las liberaba de las representaciones vigentes en torno a lo femenino ${ }^{16}$. La cuestión de género asumía, además, una dimensión jurídica fundamental en aquellas monarquías donde regía la ley sálica.

La vigencia de la ley sálica en España constituye un tema clave en el tema que nos ocupa. Es bien conocido que la ley de sucesión establecida por el Código de las Partidas establecía que las mujeres podían reinar en ausencia de hermanos varones y con preferencia sobre los varones de parentesco más lejano, y que Felipe V de Borbón modificó dicha ley en 1713. A partir de entonces, y siguiendo la tradición francesa, se impuso la ley sálica por la cual las mujeres solo podían heredar la Corona en el caso de no haber herederos varones en la línea principal (hijos) o lateral (hermanos y sobrinos). Aun cuando la ley de 1713 no excluía completamente a las mujeres del derecho de sucesión al trono, prácticamente exigía que el género masculino se extinguiera para que hubiese una reina en España. La ley de sucesión introducida durante el reinado del primer Borbón experimentó un laberíntico itinerario en el último cuarto del siglo xvinI, y especialmente tras 1808, cuando se produjo la vacatio regis. En ese momento era oficialmente desconocido que en las Cortes reunidas en 1789 , a petición del rey Carlos IV, se había anulado la ley de sucesión de 1713 para regresar a las normas establecidas por el Código de las Partidas. El rey había dado órdenes a los procuradores de que la resolución mantuviera carácter secreto una vez que se disolviesen las Cortes para no despertar apetencias por parte de las potenciales ramas herederas al trono. Faltaba solamente formalizar el acto por medio de una ley, cédula o pragmática. Pero la inquietud que mostraron las Cortes de Francia y de Nápoles, a las que habían llegado noticias de lo acontecido en Madrid a pesar de la promesa de guardar secreto, condujo a mantener la decisión reservada y a no publicar el acto $^{17}$. Lo resuelto en las Cortes de 1789 se inscribía en la política carlotercerista de acercamiento de las dos coronas ibéricas, cuando Floridablanca -ministro encargado de arreglar en 1785 los matrimonios con los infantes portugueses - alentó el regreso a la sucesión femenina para una eventual unión con Portugal ${ }^{18}$.

16 Gutiérrez et al. (2014).

17 Cuando se publicó la Novísima Recopilación de Leyes de 1805 no apareció esta resolución (Anes, 1975).

18 López Cordón (2003). 
Lo cierto es que, llegados a 1808, todas las cuestiones hasta aquí reseñadas confluyeron en un contexto de crisis política y legal sin precedentes. La tensión entre principio dinástico y equilibrio de potencias, el debate entre antigua y nueva constitución y el conocimiento que tomó por esos días la abolición de la ley sálica en las Cortes de 1789, colocaron a la infanta Carlota Joaquina en el centro de disputas políticas que, además de reflejar los intereses contrapuestos de las potencias y de los partidos existentes en la península, revelaron el perfil de una mujer con fuerte vocación de poder. Este perfil ya lo había exhibido antes de su partida a Río de Janeiro, al buscar involucrarse en la política portuguesa. Como señala López Cordón (2014: 65), Carlota no se resignaba a tener un papel secundario cuando se convirtió en 1799 en regente consorte de Portugal — al asumir su marido la regencia por enfermedad mental de su madre, la reina María I- y protestó abiertamente por quedar excluida de participar en los debates del Consejo, como lo habían hecho su madre, su abuela y su bisabuela en España. Tampoco renunció a ser partícipe de una conspiración en 1806 organizada en Lisboa por un sector de la nobleza portuguesa que, frente a una prolongada enfermedad del príncipe regente que se temía similar a la demencia que sufría su madre, buscó elevar a su esposa Carlota a la regencia. La conspiración fue descubierta, los involucrados castigados, y con la infanta las relaciones conyugales habrían quedado severamente resentidas si no definitivamente rotas ${ }^{19}$. Carlota, sin embargo, después de este frustrado episodio, encontró en las renuncias de la rama masculina de su familia a la Corona una nueva oportunidad para desplegar su capacidad y voluntad de intervenir en el espacio político, ahora hispano.

\section{DOS PROPUESTAS DE REGENCIA}

Cuando en julio de 1808 llegaron a Río de Janeiro las noticias de lo ocurrido en España, la corte de Braganza actuó inmediatamente a través de la publicación de cuatro manifiestos en el mes de agosto ${ }^{20}$. El plan del Gabinete portugués consistía en establecer una regencia en América mientras el rey de

19 Marques Pereira (1999).

20 «Justa Reclamación» de Carlota Joaquina y Pedro Carlos; «Manifiesto dirigido a los Fieles Vasallos» de Carlota Joaquina; «Respuesta de S. A. R. el Príncipe Regente de Portugal» (los tres fechados en Río de Janeiro, 19 de agosto de 1808), y «Don Pedro Carlos de Borbón y Braganza al Príncipe Regente de Portugal» fechado en Río de Janeiro el 20 de agosto de 1808. Biblioteca Nacional (BN), Madrid, legajo 1155, 19511. 
España estuviese cautivo en Francia, y colocar a su cabeza a uno de los dos Borbones emparentados con los Braganza. Para el influyente ministro luso de Estado y Guerra, Rodrigo de Sousa Coutinho, futuro conde de Linhares y líder del partido filoinglés dentro del Gabinete, el candidato debía ser Pedro Carlos, hijo del hermano de Carlos IV, Gabriel de Borbón, y de la infanta Mariana Victoria de Portugal, quien al quedar huérfano de pequeño fue enviado a la corte de Braganza para criarse con su familia materna. Pero la infanta Carlota no estaba dispuesta a renunciar a los derechos que le otorgaba su linaje más directo con la familia real. En el manifiesto que la princesa firmó el 19 de agosto de 1808 sostuvo que, frente a la violencia e ilegitimidad de las abdicaciones y a la falta de libertad de toda su familia para ejercer la autoridad, se consideraba «suficientemente autorizada y obligada a ejercer las veces de mi Augusto Padre y Real Familia de España existentes en Europa, como la más próxima representante suya en este continente de América para con sus fieles y amados vasallos». A tal efecto aclaraba que «no me considero más que una Depositaria y Defensora de esos derechos que quiero conservar ilesos e inmunes de la perversidad de los franceses para restituirlos al legal representante de la misma Augusta Familia $»^{21}$.

Las fisuras que el plan de regencia provocó dentro de la corte de Braganza quedaron exhibidas en el manifiesto firmado por Pedro Carlos, al día siguiente del publicado por Carlota, al declarar que se guardaba «el derecho de antelación y preferencia que pertenece a los individuos de mi Real Familia» y exigía seguir «el orden de sucesión prefijado por las Leyes fundamentales de la Monarquía Española cuyos derechos y prerrogativas quiero se conserven del modo y forma expresados ${ }^{22}$. Según este documento, la cuestión del linaje dinástico dejaba abiertos dos problemas: el primero era la vigencia en España de la ley sálica, desde la cual el infante reclamaba su derecho de antelación frente a Carlota; el segundo era la presencia de la rama borbónica napolitana que también podía invocar sus derechos dinásticos.

Ahora bien, mientras los manifiestos bragantinos comenzaron a circular por todas las jurisdicciones hispanoamericanas, en la península — sin tener conocimiento de dichos manifiestos - se extendía la formación de juntas locales. Si bien la generalizada respuesta juntista que derivó en la creación de la Junta Central parecía no tener retorno, el Consejo de Castilla libró su batalla jurídica, apoyado por altos miembros del Ejército y algunos personajes y magistrados de peso, en pos de recuperar las riendas del conflicto. En una consulta presentada el 8 de octubre de 1808, pocos días después de crearse la

21 "Manifiesto», 19 de agosto de 1808.

22 «Don Pedro Carlos», 19 de agosto de 1808. 
Junta Central, el Consejo acusaba a las juntas provinciales de haber «conculcado sin miramientos» las «leyes del Reino» por haber "ostentado una representación que no tienen por las Leyes" y haberse creído "soberanas e independientes» resintiendo "nuestra constitución monárquica» ${ }^{23}$. El reclamo a la "observancia de las Leyes Fundamentales» se concretaba en una propuesta de regencia, avalada por la ley 3.a , partida 2. a, tíítulo 15, que preveía "guardadores» del rey en los casos de minoridad o incapacidad del mismo.

Frente a la situación extraordinaria creada por las abdicaciones, la disputa consistía en buscar respuestas jurídicas para legitimar posiciones que debían encontrar apoyos políticos para imponerse. Dentro del gran paraguas de la cultura jurídica hispana se entabló una competencia en torno a quién o quiénes debían asumir el depósito de la soberanía del rey ausente. Por un lado, las juntas seguían el guión de las teorías pactistas y reclamaban su derecho a gestionar, administrar o disponer de la soberanía ante el hecho de que recayera en los pueblos. Por el otro, se le oponían posiciones - como las del Consejo o las emanadas en la corte de Braganza- que se apoyaban en la defensa de las leyes fundamentales de la monarquía para asumir la tutela o el depósito de la soberanía real. El punto crucial era cómo resolver el dilema de un interregno que no estaba contemplado en dichas leyes ${ }^{24}$. El Consejo de Castilla, desprestigiado por haber avalado en los primeros momentos las renuncias, no encontraba una respuesta convincente en la ley de partida que preveía guardadores del rey: la situación extraordinaria de 1808 no se ajustaba a las previstas por minoridad o incapacidad. Los argumentos por analogía que invocó el Consejo no doblegaron a la Junta Central ni a las provinciales y cabe destacar que entre esos argumentos no figuró en ningún momento la propuesta de cubrir el interregno a través de una regencia encarnada por los descendientes más directos de la familia real que se hallaban libres del yugo napoleónico. Si bien el arzobispo de Toledo resonaba como uno de los candidatos más firmes para conformarla, por ser el único miembro de la familia real que permanecía en España, este no figuraba (sino remotamente) en la línea sucesoria ${ }^{25}$.

Las dos propuestas de regencia elaboradas simultáneamente en Brasil y en España no entraron hasta varios meses después en contacto, siguiendo los ritmos de circulación de las noticias a ambos lados del Atlántico y de la tardía decisión de Carlota Joaquina de entablar formalmente vínculos con las autoridades sustitutas de la península. La reticencia de la infanta a entablar tales

Archivo Histórico Nacional (AHN), Madrid, Estado, 3566, exp. 57, 170.

Sobre el interregno extraordinario de 1808 véase Garriga (2009).

25 El arzobispo de Toledo, cardenal Luis María de Borbón y Vallabriga, era hijo de Luis de Borbón, hermano de Carlos III. 
vínculos respondía básicamente al cuestionamiento que le merecían las juntas. Los argumentos para su diatriba contra el juntismo eran similares a los invocados por el Consejo de Castilla, pero se montaban en un reclamo ausente en el segundo e irrenunciable para la princesa: el de sus derechos dinásticos. Carlota afirmaba al respecto que «no reconozco a la Junta de Sevilla ni a ninguna de las otras que se han establecido en el reino, excepto en que se han conducido bien» e insistía en hacer respetar y «establecer el derecho de sucesión declarado por las Leyes del Código Nacional y reconocido por todas las naciones del mundo ${ }^{26}$.

Carlota jugó sus primeras cartas de reconocimiento a la regencia entre las autoridades coloniales americanas. Pero el inmediato rechazo que obtuvo del virreinato más cercano — el del Río de la Plata_ y la creciente convicción de que era imprescindible buscar apoyo en la península, especialmente después de tomar conocimiento de la abolición de la ley sálica en las Cortes de 1789, le decidió a iniciar sus contactos transatlánticos en noviembre de 1808. El primer paquete que contenía los manifiestos bragantinos y numerosa correspondencia, escrita y firmada de puño y letra por la infanta, estaba dirigido a las autoridades y a diversos personajes de relieve ${ }^{27}$. Entre esos personajes se encontraba el conde de Floridablanca, destinatario de una misiva muy personal por parte de la infanta en la que le agradecía su reconocimiento como la más directa y legítima heredera de los derechos eventuales al trono ${ }^{28}$. Carlota hacía referencia a la proclama de la Junta de Murcia del 22 de junio de 1808, atribuida a la pluma de Floridablanca, en la que se hizo público el «secreto» de aquellas cortes convocadas por Carlos IV y donde se proponía explícitamente que «la Señora Carlota Princesa del Brasil debía ser admitida a la Corona a falta de sus hermanos varones ${ }^{29}$. La proclama había llegado a manos de la princesa y le ofrecía un instrumento jurídico formidable para avanzar con sus planes. No obstante, la carta llegó a España cuando Floridablanca acababa de morir.

26 Carlota Joaquina a Floridablanca, Río de Janeiro, 8 de noviembre de 1808, Colección de obras y documentos para la Historia Argentina, Biblioteca de Mayo, Buenos Aires, Senado de la Nación, 1961, t. III, p. 185.

27 En un extenso informe elaborado por la Secretaría de la Junta Central para su consideración, se sintetizaban los destinatarios y contenidos de esta primera avanzada epistolar. «Informe detallado de la correspondencia relacionada con la política lusitana», s/f, Mayo Documental (MD), Universidad de Buenos Aires, Facultad de Filosofía y Letras, 1962 (MD) t. V, pp. 112-119.

28 AHN, Madrid, Estado, legajo 5837.

29 Cita extraída de Martiré (2008): 221-222. 
La reacción exhibida por el Consejo de Castilla y por la Junta Central al recibir el primer paquete de correspondencia procedente de Río de Janeiro revela la amenaza que ambos cuerpos percibieron en los planes carlotistas, habilitando al menos en este punto una coincidencia de posiciones. El Consejo condenó inmediatamente dichos planes a través de la memoria presentada por el fiscal donde se afirmaba que la Junta «era el gobierno legal que convenía» y rechazaba el reclamo a la regencia de Carlota destacando aquellos pasajes de las leyes de partidas que les eran funcionales para avalar su posición: «Estas leyes no juzgaron conveniente fuese elegido para la guarda de la persona del rey menor ni el gobierno de sus reinos y señoríos ninguno de sus parientes, pues cuerdamente advirtieron los riesgos y peligros a que se exponía no solo la sagrada persona del legítimo Rey, sino también toda la monarquía ${ }^{30}$.

El Consejo, cuya labor de zapa contra la Junta Central continuaba vigente $^{31}$, en esta oportunidad cerraba filas con ella en contra de un mismo contendiente que basaba sus derechos en el linaje dinástico. La alarma provenía de dos amenazas latentes. La primera era la potencial americanización de la monarquía; la segunda, la desconfianza secular que España mantenía hacia Portugal, más allá del reciente y forzado cambio de alianzas internacionales. El temor a que las autoridades coloniales apoyaran una regencia americana quedaba exhibida en la memoria del Consejo recién citada al postular que los infantes debieron dirigirse directamente «a la metrópoli» y no a las ciudades y ayuntamientos de las posesiones americanas ${ }^{32}$. Dicho temor se reforzaba, además, con la posibilidad de que los Braganza aprovecharan la situación para consumar la unidad de las dos coronas ibéricas con sede en Brasil. El fantasma para las autoridades peninsulares era lo que efectivamente alentaba el sector más influyente del gabinete luso, liderado por su ministro de Estado: cumplir el sueño de reconstituir el mundo de Felipe II, pero ahora, frente a la debilidad de España, bajo la hegemonía portuguesa; un sueño que albergaba la estrategia expansionista lusitana en América que le había enfrentado hasta allí con la potencia vecina. La mutua desconfianza de base dinástica, que hundía sus raíces en la experiencia de unión de las dos monarquías entre 1581 y 1640 , se reactualizaba ahora en una situación extraordinaria y explosiva ${ }^{33}$.

En ese escenario se decidió regularizar las relaciones diplomáticas entre España y Portugal, interrumpidas en 1807 como consecuencia del Tratado de

\footnotetext{
Fiscal Nicolás María de Sierra, Madrid, 1 de marzo de 1809, MD, t. VIII, pp. 59-61. Artola Gallego (1978).

Fiscal Nicolás María de Sierra, p. 61.

33 Sobre la experiencia de unión de las dos monarquías ibéricas en los siglos XVI y XVII, véase Cardim (2014).
} 
Fontainebleau, en el que la primera había previsto junto con Francia el reparto de la segunda. Apenas llegaron las novedades de Brasil, la Junta Central, en concordancia con el Consejo de Castilla, puso en marcha un plan destinado a neutralizar por todos los medios los planes de los Braganza, y especialmente los de Carlota Joaquina que, a esa altura, había ganado autonomía dentro de su propia corte para liderar su candidatura a la regencia en oposición a su primo Pedro Carlos. La competencia que la princesa podía ejercer en torno al depósito de la soberanía era, al menos en la percepción de los peninsulares, demasiado peligrosa y por ello había que actuar rápidamente. A tal efecto, el 22 de febrero de 1809 se designó como enviado extraordinario y ministro plenipotenciario de España en la corte portuguesa de Río de Janeiro al marqués de Casa Irujo, cuyas instrucciones estaban básicamente concentradas en sustraerle a Carlota toda legitimidad en su comunicación con los dominios hispanoamericanos y en controlar de cerca todos sus movimientos. Al mismo tiempo, fue nombrado Pascual Tenorio y Ruiz de Moscoso como encargado interino de los negocios de Espańa en Lisboa y, como contrapartida, fue designado como embajador del príncipe regente de Portugal en España Pedro de Sousa Holstein, futuro conde de Palmela y sobrino de Rodrigo de Sousa Coutinho ${ }^{34}$.

Las legaciones diplomáticas hispanas y lusas comenzaron a actuar en sus respectivos destinos, mientras la diplomacia británica intervenía activamente a través de sus representantes y la francesa se mantenía atenta a los movimientos de sus enemigos. Domingos Sousa Coutinho, hermano del influyente ministro de Estado portugués, ocupaba la legación portuguesa en Londres, y Lord Strangford la representación británica en Río de Janeiro. Las tres potencias aliadas, a pesar del vínculo que ahora las unía contra el enemigo francés, muy pronto descubrirán los intereses contrapuestos que las enfrentaban, especialmente cuando se pusieron en juego los planes dinásticos encarnados por Carlota.

\section{LA DIPLOMACIA EN ACCIÓN}

A mediados de 1809 llegó a Sevilla Pedro de Sousa Holstein. En sus instrucciones, el Gobierno portugués le fijaba tres objetivos: negociar un tratado de alianza y comercio con Espańa, conseguir la devolución de Olivenza y defender los derechos de Carlota Joaquina a la sucesión al trono. En la correspondencia que el embajador mantuvo con el ministro de Estado portugués, a

34 Lima (2006); López Cordón (2003); Marques Pereira (1999), y Rubio (1920). 
los pocos días de su llegada a destino, le informaba de la reticencia que frente al tema de la sucesión observó en las conversaciones privadas mantenidas con Martín de Garay, el entonces presidente de la Junta, y confesaba que con el ministro inglés en Sevilla, Richard Wellesley, no se había atrevido a tratar dados los temores que los Gobiernos británicos mantenían frente a la potencial unidad de las dos coronas ibéricas ${ }^{35}$.

Tales temores se habían puesto de manifiesto poco después de la publicación de los manifiestos bragantinos a través de las gestiones del ministro lord Strangford en Río de Janeiro, férreo opositor a los planes encarnados por la infanta y por la corte portuguesa. La voluminosa correspondencia de lord Strangford con el Gabinete británico a cargo de George Canning — ministro de Relaciones Exteriores - y lord Castlereagh — secretario de Estado y Guerra- y la intercambiada por estos ministros con los sucesivos enviados ingleses en Espańa revela el delicado equilibrio en el que se encontraba Inglaterra frente a la situación española y las apetencias lusas ${ }^{36}$. La desconfianza del Gabinete inglés hacia el movimiento juntista español —la misma que había demostrado frente al efímero movimiento juntista portugués que logró disolver- se hizo manifiesta inmediatamente al evaluar la opción de una regencia. George Canning reflexionaba en una carta fechada en octubre de 1808 dirigida a John Frere, por entonces embajador inglés en Espańa, acerca de la alternativa de una regencia a cargo de Carlota Joaquina para «mantener el principio monárquico» y desalentar las «innovaciones republicanas» o «cualquier tipo de gobierno por comités o por presidentes periódicos elegidos popularmente ${ }^{37}$. Pero reconocía que esa opción podía abrir conflictos dinásticos con la casa de Nápoles en el caso de que también reclamara su derecho a una regencia. Frente a esta potencial tensión, Canning se inclinaba en ese momento por apoyar una regencia encarnada por el arzobispo de Toledo, en sintonía con los

35 Sousa Holstein al Conde de Linhares, Sevilla, 2 de agosto de 1809, Archivo Ministerio Relaciones Exteriores (AMRE), Río de Janeiro, Legación en Sevilla, 1809-1810 (338/02/06), Off. N. 8.

36 Parte de esa documentación puede consultarse en: Foreign Office Archives, Britain and the Independence of Latin America 1812-1830. Select Documents from the Foreing Office Archives. 2 vols., Londres, Oxford University Press, 1938; Archivo General de la Nación, Politica lusitana en el Río de la Plata, 1808-1815 (Colección Lavradio), 3 vols., Buenos Aires, 1961; Archivo General de la Nación, Correspondencia de Lord Strangford y de la Estación Naval Británica en el Río de la Plata, Buenos Aires, 1941; Barrow, John (ed). The life and correspondence of Admiral Sir Sydney Smith, 2 vols., London, Richard Bentley, 1848.

$37 M D$, t. III, p. 240. 
argumentos que el Consejo de Castilla expuso en su consulta presentada el 8 de octubre de 1808. Sin embargo, la Junta Central se impuso y la diplomacia británica actuó sobre los hechos consumados tratando de evitar a partir de entonces el riesgo de una unidad ibérica.

Carlota Joaquina intentaba despejar frente a Gran Bretańa el fantasma de la potencial unidad dinástica en una carta dirigida al príncipe regente de Inglaterra en la que afirmaba que sus «intenciones en caso de que se verifique mi ascensión al trono de España» eran mantener dicha Corona «absolutamente independiente, en la misma forma y manera que se ha mantenido el reino de Nápoles por el Tratado de Utrecht evitando así la reunión de dos coronas en una misma cabeza y guardando un equilibrio perfecto, buscando que las dos naciones gocen de sus derechos, costumbres, leyes y lenguaje, ya que esto sería impracticable y hasta ilusorio bajo cualquier otro sistema ${ }^{38}$.

En esta oportunidad, Carlota hablaba el idioma post Utrecht y a la vez dejaba en evidencia la tensión ya señalada entre una lógica dinástica, la búsqueda de equilibrios geopolíticos y las credenciales nacionales que exhibían las monarquías. Si la primera lógica dominó la argumentación de los manifiestos bragantinos (donde las palabras "casa», «familia» $\mathrm{y}$ «sangre» representaron las bases de los reclamos), las dos restantes emergían como producto de las negociaciones políticas "para evitar toda sospecha de interferencia e intervención de un ministerio y gobierno extranjeros, cuyas jurisdicciones deben estar eternamente separadas», según aclaraba la infanta ${ }^{39}$.

Pero nada podía convencer a la potencia de la que dependía el futuro de la guerra contra Napoleón y el tablero político internacional. Strangford, además de desacreditar a la princesa en sus oficios enviados a Canning, intervenía directamente frente al príncipe regente de Portugal advirtiéndole que «el gobierno británico desaprueba de plano todo proyecto que tenga por fin el menor cambio de los negocios de la América española» y que había «recibido orden de oponerse, en nombre de mi Soberano, quien no cree que haya llegado el momento de plantear las pretensiones de la Señora Princesa del Brasil» ${ }^{40}$.

No obstante, el proyecto de reconocimiento de los derechos de la infanta siguió su curso por las vías diplomáticas y políticas. En agosto de 1809 se le presentó a Sousa Holstein la primera oportunidad de hacer valer dichos

38 Carlota Joaquina al príncipe regente de Inglaterra, Río de Janeiro, octubre de 1808, $M D$, t. III, p. 185.

39 Id.

40 Strangford al príncipe regente de Portugal, Río de Janeiro, 29 de marzo de 1809. Colección Lavradio, t. 1, p. 477. 
derechos al presentar una consulta el ahora Consejo Reunido, que recogía el programa presentado por el Consejo de Castilla en octubre de 1808 de crear una regencia - el candidato más firme seguía siendo el arzobispo de Toledoy de disolver la Junta Suprema y las juntas provinciales ${ }^{41}$. La disputa por el depósito de la soberanía continuaba vigente en un clima en el que los resultados de la guerra contra Francia no eran para nada alentadores y en el que el tema de la convocatoria a Cortes se hacía cada vez más omnipresente.

En el marco de la consulta presentada por el Consejo, Pedro de Sousa Holstein debutó públicamente como plenipotenciario enviando una misiva a la Junta Central en la que, luego de aclarar que su intervención se debía a que «se ha esparcido por todo el público la voz de que esta Suprema Junta [...] viene desde hace unos días a esta parte discutiendo el proyecto de entregar en la crisis actual el Gobierno de esta vasta Monarquía a un Consejo de Regencia», en tal situación se veía obligado, como representante de la corte de Braganza, a "promover no solo los derechos sino también los intereses de la Princesa Doña Carlota Joaquina de Borbón» a ocupar la cabeza de esa regencia. Si bien invocó en la carta que dichos derechos quedaron «confirmados por las Cortes de 1789", su intervención fue muy cauta puesto que se limitó al tema que estaba en discusión - la regencia - sin avanzar en su instrucción sobre el reconocimiento de sus derechos sucesorios ${ }^{42}$.

En realidad, una vez conocidas las resoluciones secretas de las Cortes de 1789, la corte portuguesa y la propia princesa apuntaron a la doble estrategia de imponer una regencia, primero en América y luego a escala de toda la monarquía, y de ser admitida formalmente en la línea sucesoria. La primera demanda presuponía limitarse a asumir el depósito de la soberanía vacante, mientras la segunda implicaba formalizar lo decidido en aquellas Cortes por medio de una ley, cédula o pragmática. Las negociaciones de los portugueses buscaron diferenciar ambas cuestiones y medir, en cada coyuntura, la mejor oportunidad de barajar una u otra o las dos al mismo tiempo. Ahora bien, a pesar de que ni la propuesta de regencia del Consejo Reunido ni menos aún la del ministro luso tuvieron apoyos para imponerse, algunas intervenciones de la consulta y, sobre todo, las tratativas que en las sombras había iniciado Sousa Holstein, revelan las redes que por esos días se fueron conformando en Espańa en torno a la alternativa carlotista.

En las misivas que el plenipotenciario portugués envió a la corte de Braganza para informar sobre lo ocurrido, quedan al descubierto los entretelones

41 Para un desarrollo detallado de la Consulta de 1809, véase Ternavasio (2013).

42 AHN, Madrid, Estado, legajo 3666 (2), expediente 57. 
de las negociaciones políticas que comenzaban a llevarse a cabo ${ }^{43}$. El ministro relataba que si bien no había logrado el apoyo del plenipotenciario británico, quien muy diplomáticamente se comprometió a guardar en el asunto «una perfecta indiferencia», su intervención no había caído en saco roto, puesto que contó con la valiosa colaboración de Benito Ramón de Hermida, encargado del despacho de Gracia y Justicia, quien operó de informante oficioso de lo que se discutía en el seno de la Junta. Pero no solo eso: la respuesta oficial de Hermida a la consulta fue la defensa, sin reticencias, de la opción de instaurar una regencia encarnada por la infanta Carlota Joaquina de Borbón, por ser «el más próximo heredero del reino [...] en cuya persona y descendencia, a falta de familia Real cautiva, se deben reunir los Cetros de Espańa y América con los de Portugal y el Brasil, ventaja incalculable siempre deseada y procurada con los enlaces que la razón de estado tenía por máxima multiplicar entre las casas de España y de Braganza» ${ }^{44}$.

Hermida afirmaba que si «fuese preciso abandonar la Península», resultaba de fundamental importancia contar con la alternativa del «establecimiento del Imperio Español en el nuevo mundo" y de "presentar a sus dilatadas y separadas provincias en centro común de unión y de grandeza aumentada con el Brasil $»^{45}$. La opción de americanizar la monarquía y de proyectar dicha americanización como una unión ibérica dominada por España y no por Portugal evitaría, según Hermida, el riesgo de que los dominios ultramarinos tomaran el camino de la independencia.

La propuesta del ministro de Gracia y Justicia español no era producto de una improvisada argumentación en medio de la crisis por la que transitaba la Junta Central ${ }^{46}$. Cabe destacar que entre la correspondencia recibida por la princesa en Río de Janeiro se hallan varias cartas que le dirigió Benito Ramón de Hermida, y la primera está fechada el 26 de junio de 1808, en la que le declaraba que desde el 24 de mayo en que se produjo, «la revolución en Zaragoza» demostró que la intervención real era indispensable para «sostener la unión y energía popular» y que sus esfuerzos «públicos» $\mathrm{y}$ "privados»

43 Sousa Holstein al conde de Linhares, Sevilla, 2 de septiembre de 1809, AMRE, Río de Janeiro, Legación en Sevilla (338/02/06), Off., N 20.

44 AHN, Madrid, Estado, legajo 3666 (2), expediente 57.

45 Id.

46 Benito Ramón Hermida fue un férreo defensor de la opción de constituciones históricas españolas como fundamento de la reforma. Luego, como diputado en las Cortes de Cádiz, además de ser uno de los principales apoyos de los planes carlotistas, presentó un tratado en el que postulaba como ejemplo la Constitución de Navarra para ser adoptado en Cádiz. Véase Busaall (2005). 
dirigidos a imponer la presencia de la infanta habían chocado con la ley sálica ${ }^{47}$.

\section{LA DIPLOMACIA ESPAÑOLA DESDOBLADA}

El ministro portugués contaba, además, con el apoyo que, desde las sombras, le otorgaba el cónsul general de España en Lisboa, Pascual Tenorio y Ruiz de Moscoso. Este personaje se había instalado con su familia en Portugal en 1796 como parte de la comitiva que acompańó a Lisboa al infante espańol Pedro Carlos luego de la muerte de sus padres y, según algunos testimonios, había estado involucrado en la conspiración de 1806 que intentó colocar a Carlota al frente de la regencia portuguesa. La sospecha que despertó su supuesta participación fue que dicha conspiración había sido instigada por el Gobierno español para anexionarse Portugal ${ }^{48}$. Si bien el episodio sigue siendo bastante oscuro, ilumina la conexión de Moscoso con la infanta y su activa colaboración en pos del objetivo del que se sospechó en 1806: unir las dos coronas ibéricas a través de Carlota Joaquina ${ }^{49}$. De hecho, poco después de la consulta de agosto de 1809, le informaba en una misiva a la princesa de que, a pesar del revés sufrido allí por su candidatura, estaba persuadido de que finalmente se establecería una regencia presidida por el cardenal de Borbón y que, una vez instalado en ella, el prelado la llamaría a ocupar el cargo. Moscoso le aseguraba que trabajaba en consonancia con Sousa Holstein y que «los puentes están bien tendidos» para tomar «la heroica resolución [de la infanta] de venir a este reino, en cuyo caso se puede casi asegurar que no habrá la menor duda en entregar la Regencia de España en manos de V.A.R. y se puede afirmar que si estuviera en el continente, ya estaría V.A.R. ejerciendo la Soberanía en España por el voto general de una Nación ${ }^{50}$.

Los puentes a los que aludía Moscoso parecen indicar que lo que se estaba cocinando entre algunos personajes de peso en la península era la alternativa de unión de las dos coronas ibéricas bajo la hegemonía española: «Un negocio — afirmaba Moscoso - en que no va menos que la feliz reunión de estas dos

47 La colección de la correspondencia entre Hermida y Carlota Joaquina se encuentra en Archivo Histórico Museo Imperial (AHMI), Petrópolis, I-POB-16.3.811-He.c 1-3.

48 Marques Pereira (1999): 64.

49 La correspondencia entre Carlota Joaquina y Pascual Tenorio y Ruiz de Moscoso, e incluso con la esposa del cónsul, es muy profusa y se encuentra en el AHMI de Petrópolis. Ambos mantenían informados a la infanta de los sucesos en Portugal y España.

50 Ruiz de Moscoso a Carlota Joaquina, Lisboa, 20 de octubre de 1809, MD, t. X, p. 77. 
Monarquías, bajo una sola autoridad, ventaja tan conocida para todo el resto de Europa, ya que solo por este medio se podrá formar una Potencia capaz de equilibrar la balanza política, tanto en el continente como en Ultramar ${ }^{51}$.

Mientras el representante español en Lisboa jugaba secretamente sus cartas a favor de los planes de Carlota, la diplomacia instalada en Río de Janeiro a través del marqués de Casa Irujo debía lidiar con instrucciones muy precisas de su Gobierno para vetar dichos planes. Tales instrucciones revelan los temores de la Junta Central y luego de la regencia formada a comienzos de 1810 frente a la alternativa que se abría de una potencial americanización de la monarquía. Irujo tuvo que enfrentar en el escenario carioca las presiones de la corte de Braganza, las de la propia infanta en permanente conflicto con su esposo y el Gabinete luso, las de lord Strangford, y luego las procedentes de los movimientos revolucionarios surgidos en Sudamérica —especialmente en Buenos Aires, la capital virreinal más cercana- cuando llegaron las noticias de la disolución de la Junta Central.

En esa encrucijada, el embajador español informaba a las autoridades peninsulares de la situación apenas desembarcó en Río de Janeiro en agosto de 1809. A pesar de sus instrucciones, en dicho informe se percibe una sutil inclinación a prestar oídos y tomar en consideración los dichos planes de Carlota. Irujo afirmaba que la princesa se conducía con "prudencia», "talento» y un "gran juicio», que era "española de corazón" y no mostraba parcialidad hacia «la Nación en que vive» y que podía asegurar de sus «sentimientos de honor, fidelidad y amor hacia su hermano nuestro desgraciado Monarca ${ }^{52}$. Sin duda que el ministro no se engańaba respecto de las apetencias de la corte de Braganza: «Si desgraciadamente tenemos que llevar en Europa el yugo del vencedor, hará el gobierno portugués uso del nombre de la Princesa a quien trata en el día con poquísimo decoro para el logro de sus fines y que la Inglaterra se valdrá del mismo pretexto». No obstante, se permitía en esta misiva aconsejar a las autoridades acerca de la propuesta de formar una regencia presentada por el Consejo Reunido en la consulta: "Con todo yo no dejaré de hacer justicia a las excelentes cualidades esenciales de S.A. que rodeada de consejeros sabios y virtuosos podría ser más útil en el caso de que la Nación pensara en adoptar algún plan de la naturaleza del que dicen ha propuesto el Consejo ${ }^{53}$.

Casa Irujo estuvo tensionado durante toda su gestión diplomática (que se prolongó hasta 1812) entre acatar estrictamente las órdenes emanadas de las
Id.
52 Marqués de Casa Irujo, Río de Janeiro, diciembre de 1809. AHN, Madrid, Estado, legajo 3783, N 14.
Id.

53 
autoridades peninsulares o promocionar la postulación de la infanta como una suerte de mal menor frente a las alternativas que se abrían y que temía funestas para la monarquía que representaba. Su estancia americana le permitía percibir mucho más de cerca las amenazas que se cernían sobre el futuro de las posesiones ultramarinas como asimismo las que representaban los Braganza con sus apetencias sobre el Atlántico Sur. La teoría del mal menor también la manejaba el propio Gabinete luso, más inclinado a garantizar sus objetivos con la postulación del sumiso infante Pedro Carlos que con la de la temeraria y más españolizada infanta Carlota; pero el ministro de Estado portugués, principal sostén de esta posición, era consciente de las mayores posibilidades que tenía de imponer a la princesa dada la directa línea sucesoria que esta exhibía.

Por su parte, la diplomacia francesa instalada en Madrid también estaba atenta a las negociaciones que se vislumbraban en torno a la corte de Braganza. El embajador galo, Laforest, informaba a París en septiembre de 1809 de que le habían llegado «rumores» a través de algunos «espías» de que «barcos de guerra han estado en el Brasil para ofrecer la Corona al Infante Don Pedro», pero «que el orden de sucesión llamaría antes que él a la princesa del Brasil, hija de Carlos IV». Señalaba que algunas versiones afirmaban «que el príncipe portugués ha renunciado, al casarse, a sus derechos de este tipo», pero que el conde de Floridablanca «sostuvo hasta su muerte que esta renunciación era ilusoria y que, por el contrario, éste había prestado especial cuidado a la reserva de los derechos de la Princesa ${ }^{54}$. Laforest aseguraba, por otro lado, que tenía la versión (que consideraba la más segura) de que se había producido una «revolución» y que «el sector democrático» es el que «ha tomado todos los poderes». Agregaba, finalmente, que «a pesar de los elementos democráticos [...] parece que para no chocar a las costumbres nacionales los dirigentes evitan todavía atacar de frente a las nociones monárquicas " ${ }^{5}$. Pocos días después, en un nuevo informe, calificaba a la Central como "una junta en delirio» y que "nada indica que el partido de la regencia triunfara hasta el momento ${ }^{56}$.

Todas las legaciones diplomáticas estaban, pues, pendientes de la cuestión dinástica y especialmente de los reclamos procedentes de la corte bragantina. En ese contexto, el marqués de la Romana le escribía en marzo de 1810 al embajador portugués en Espańa, preocupado por las noticias del futuro casamiento de Napoleón con la hija de Francisco I, emperador de Austria. El enlace, según el militar español, tornaría a Bonaparte en «jefe de la familia Borbón» y, en ese caso, opinaba que «preferiría ver a D. Carlota como reina,

54 Laforest a Champagne, Madrid, 19 de septiembre de 1809. MD, tomo X, N 1171.

55 Id.

56 Laforest a Champagne, Madrid, 31 de septiembre de 1809. MD, tomo X, N 1183. 
pues D. Fernando sería obligado a someterse a Napoleón $»^{57}$. Al mismo tiempo, los reclamos elevados por la rama borbónica del reino de Nápoles y las Dos Sicilias concitaban también cierta preocupación, habida cuenta que el rey Fernando I había enviado una carta a Río de Janeiro afirmando que sus eventuales derechos al trono español estaban garantizados por las potencias europeas en diversos tratados ${ }^{58}$. A tal efecto, el conde de Linhares instruía en octubre de 1810 a su hermano, embajador en Londres, acerca de tales apetencias. El ministro, recelando de que sus majestades «procuren que la Gran Bretańa los prefiera para ser escogidos como soberanos de este vasto continente, pasando por alto los reconocidos derechos eventuales de S.A.R la Princesa Nuestra Señora», proponía postular en su reemplazo al hijo de Carlota, el infante Miguel $^{59}$. Si tal alternativa no era de la apetencia británica, se lo instruía al ministro plenipotenciario a indagar la posibilidad de ofrecer en casamiento a una de las hijas de la infanta con uno de los hijos de S.M. Británica y aspirar a «esta nueva línea que se formaría al darle un principado en la América Española [... y servir de enlace a las dos augustas reales familias ${ }^{60}$.

Aunque las opciones que presentaba el ministro de Estado portugués parecen irrealizables, en una coyuntura en la que las Cortes acababan de reunirse y de imputar la soberanía a la nación, es cierto también que la percepción que muchos de estos personajes tenían de dichas Cortes, dominadas por el partido liberal, confinadas en la isla de León y protegidas por la escuadra inglesa, era que la situación revolucionaria podía cambiar de un día para el otro con una península prácticamente ocupada por las tropas de Francia. El futuro era imprevisible y las potencias buscaban proyectar ese futuro según sus intereses geopolíticos, pero también según los horizontes jurídicos, culturales y mentales que por siglos habían modulado un orden profundamente trastocado después de 1789.

\section{EL LINAJE DINÁSTICO EN SUSPENSO}

El fantasma revolucionario de 1789 que actualizó la situación de España quedó claramente expuesto en el testimonio de Sousa Holstein, apenas llegó a Sevilla:

57 Pedro Caro y Sureda, Marqués de la Romana, Badajoz, 31 de marzo de 1810. AHMI, Petrópolis, I-POB-31.3.810-Caro.c.

58 Palermo, 6 de febrero de 1809. AHMI, Petrópolis, I-POB-6.2.809-FI.DS.c.

59 Colección Lavradio, tomo 2, p. 147.

60 Id. 
La revolución de Francia tuvo por objeto la destrucción del Trono, de los Altares, y de la Nobleza. La de España comenzó con intentos enteramente opuestos a los dos primeros; pero va manifestando claramente el proyecto de abatir (si no destruir) a la Nobleza. Y no se puede dudar que a este primer golpe le seguirá el de reformar las grandes riquezas del clero; y muy probablemente el de disminuir el poder del Soberano!

En una palabra, créame V.E. que no me engańo. Excepto en los grandes y en la ínfima clase de la nación, se conoce en toda ella, que debajo del aparente deseo de reformas hay una clara tendencia al Republicanismo. La unanimidad de voluntades que caracterizaron el comienzo de esta Revolución está siendo reemplazada por la más vasta intriga de la que la Junta Central es verdaderamente el foco ${ }^{61}$.

En diciembre de 1810, tres meses después de reunirse las Cortes, el mismo ministro afirmaba que la convocatoria a la Asamblea Constituyente se podría haber evitado si la Junta Central hubiese instalado una regencia en lugar de asumir el mando político de la acéfala monarquía española ${ }^{62}$. En este juicio de tono apesadumbrado, el embajador portugués admitía que la dinámica de los acontecimientos y la correlación de fuerzas imperantes había conducido a un desenlace que, como se dijo al comienzo de este artículo, no podía preverse en mayo de 1808 y que ya había quedado delineado unos meses antes de disolverse la Central, cuando se impuso la propuesta de Lorenzo Calvo de Rozas de convocar cortes constituyentes unicamerales y electivas. Pero, además, era el reconocimiento del fracaso de su gestión, al menos en una de sus dimensiones cruciales: imponer una regencia de linaje dinástico que, asumiendo el depósito provisional de la soberanía real, resolviera el interregno producido por la vacante y desplazara cualquier alternativa que alterara el orden vigente.

Ese fracaso, sin embargo, no impidió que la corte de Braganza continuara avanzando con el ambicioso objetivo inicial, explícito en las instrucciones otorgadas a su ministro en España. En este punto es pertinente destacar que Sousa Holstein procuró actuar contrarreloj cuando, advirtiendo la crisis final de la Junta Central y la inminente convocatoria a Cortes Generales, presionó la

61 Sousa Holstein al Conde de Linhares, Sevilla, 2 de agosto de 1809, AMRE, Río de Janeiro, Legación en Sevilla, 1809-1810 (338/02/06) Off. N 11. La traducción del original es nuestra. Agradezco la generosidad del Dr. Joáo Paulo Pimenta por haberme facilitado documentación del archivo citado.

62 Sousa Holstein al Conde de Linhares, Cádiz, 31 de diciembre de 1810, Reservados, Biblioteca Nacional de Portugal, Off. N 23. 
decisión de ver reconocidos los derechos eventuales de Carlota Joaquina a la Corona. En una misiva dirigida el 30 de noviembre de 1809 a Francisco Saavedra, secretario de la Junta Central, le reclamaba «que la declaración de los derechos de la serenísima Señora Princesa D. Carlota Infanta de España, a la sucesión eventual de estos reinos sea el primer objeto sobre el cual el gobierno llame la atención de esa Asamblea». Para sembrar la zozobra entre sus interlocutores, apelaba al incierto futuro del rey cautivo argumentando que luego de la «desastrosa paz de Austria», Napoleón "podía cometer otra atrocidad» quitando la vida a Fernando VII y a su hermano Carlos María Isidro. Era urgente, entonces, acelerar una decisión, aunque esto implicara «salir de las reglas ordinarias sin consultar ni la justicia ni la constitución de la monarquía» ${ }^{63}$. La primera respuesta de Saavedra fue que en los momentos críticos que se vivían era «impracticable», «intempestivo» y hasta "perjudicial» que la Junta decidiera un asunto de tal naturaleza. Además de recordarle al ministro luso que la resolución de las Cortes de 1789 no "habían sido publicadas", que se trataba de una atribución propia de la representación en Cortes y que, una vez reunidas estas, le darían la primera atención a la sucesión de la Corona y a los derechos de la infanta $^{64}$, lo que silenciaba Saavedra en esa misiva era lo discutido por la sesión ejecutiva de la Junta Central el día anterior en la que se expuso «el desagrado de Inglaterra por la unión posible de la península» ${ }^{65}$.

A pesar de esta actitud reticente y de las presiones diplomáticas recibidas por la potencia que dirimía el futuro de la guerra contra Francia, la Junta resolvió finalmente derivar el asunto al Consejo Supremo de España e Indias para formar un expediente «interpelando las personas existentes en el día en Sevilla que concurrieron» a las Cortes de 1789 con el fin de recabar «noticias y datos ${ }^{66}$. Se trataba de una verdadera pesquisa que requería develar el enigma de aquellas Cortes. El embajador portugués no perdió tiempo y puso en marcha sus contactos políticos. En una misiva dirigida al ministro de Estado en Río de Janeiro, le informaba que "procuró persuadir a varios miembros de influencia en el gobierno» con el objetivo de que el Consejo Reunido se expidiera favorablemente en quince días y que luego la Junta publicara los derechos a la sucesión de la infanta ${ }^{67}$. El temor a que el asunto quedase definitivamente desplazado hacia las futuras e inminentes Cortes era explícito.

63 AHMI, Petrópolis, II-POB-24.4.809-Cj.P.do 1-8.

64 Sevilla, 15 de diciembre de 1809, AHMI, Petrópolis, II-POB-24.4.809-Cj.P.do 1-8.

65 "Oficio de la Junta Central», Sevilla, 14 de diciembre de 1809, AHMI, Petrópolis, II-POB-24.4.809-Cj.P.do 1-8.

66 Sevilla, 31 de diciembre de 1809, AHMI, Petrópolis, II-POB-24.4.809-Cj.P.do 1-8.

67 Sevilla, 29 de diciembre de 1809, AHMI, Petrópolis, II-POB-24.4.809-Cj.P.do 1-8. 
Lo cierto es que pocos días antes de que los acontecimientos bélicos precipitaran la disolución de la Junta Central, el Supremo Consejo había respondido a la consulta confirmando las pretensiones de la corte lusitana y los derechos sucesorios a favor de Carlota. Francisco Saavedra, en nota oficial a Sousa Holstein, reconocía la abolición de la ley sálica y los reclamos de la princesa $^{68}$. Los dos cuerpos que hasta allí se habían resistido a la regencia dinástica aceptaban lo actuado por las Cortes de 1789. El Consejo de Regencia formado a fines de enero de 1810, según los dichos de Sousa Holstein, habría reafirmado lo decidido por el Consejo pero, tal como había ocurrido dos décadas atrás, la publicación oficial de esta resolución quedó en suspenso y a la espera de las decisiones que tomaran las Cortes. El propósito de apurar una resolución sin seguir las reglas ordinarias, como había sugerido el ministro portugués, no pudo evitar que un tema tan sensible y que se encontraba entre aquellos pocos que no eran susceptibles de modulación por la tradición, pasara a ser debatido por la Asamblea reunida finalmente en septiembre de 1810 .

A pesar de los temores de los portugueses y del predominio de los grupos liberales, esas Cortes terminaron constitucionalizando el linaje dinástico de Carlota luego de intensos debates y negociaciones políticas desplegados tanto dentro como fuera del recinto ${ }^{69}$. De hecho, el trabajo realizado por el ministro portugués, Pedro de Sousa Holstein, para alcanzar los votos que se requerían en las Cortes en pos de aprobar la ley de sucesión fue premiado por la corte portuguesa otorgándole el título de Conde de Palmela. Pero como suele ocurrir con ciertas trayectorias de vida, las convicciones que en aquellos años supo defender el joven diplomático luso al profesar una clara adhesión al orden monárquico absoluto contrastan con sus posicionamientos posteriores, cuando después de 1820 se convirtió en uno de los paladines del liberalismo moderado portugués. Un contraste que el propio conde de Palmela se encargó de silenciar en sus memorias, publicadas recientemente y en las que - como ha destacado Costa (2013: 88) — están prácticamente ausentes sus gestiones como representante de la monarquía lusa en España ${ }^{70}$.

El proceso selectivo que revela esta autobiografía bien puede servir de espejo del que dominó por mucho tiempo en las historiografías nacionales, atravesadas por las disputas entre liberales y absolutistas. Los planes dinásticos de la infanta Carlota quedaron así atrapados en la construcción de leyendas

\footnotetext{
68 AHMI, Petrópolis, II-POB-24.4.811-Ho.o 1-11.

69 Sobre el debate de los derechos de Carlota en las Cortes véanse: Brancato (2003); Costa (2013); Marques Pereira (1999); Martiré (2006); Nogueira de Azevedo (2002), y Ternavasio (2015).

70 Bonifácio (2011).
} 
negras o doradas que poco contribuyeron a interrogarse sobre los conflictos de naturaleza política que desataron en el escenario transatlántico. La historiografía más renovada sobre el proceso desplegado durante este bienio ha hecho hincapié en la naturaleza inédita del movimiento juntista español que desembocó en la Asamblea Constituyente y en la formación de regencias a cargo del poder ejecutivo provisorio. Sin embargo, las disputas que desató la competencia por el depósito de la soberanía vacante y luego por encarnar una regencia dinástica iluminan el íntimo entrelazamiento entre las fuerzas políticas locales nacidas de la crisis monárquica y las principales potencias con las que España quedó repentinamente conformando una inestable y conflictiva alianza. Para fines de 1810 el futuro de esa monarquía seguía en suspenso, y si bien el triunfo de la estrategia más ambiciosa de la corte de Braganza de ver reconocidos los derechos sucesorios de la infanta en la Constitución de 1812 no forma parte de este ensayo, es oportuno cerrarlo advirtiendo lo que anunciamos al comienzo: dicho triunfo solo se hace inteligible si se inscribe en las redes de vínculos que comenzaron a trabarse entre representantes diplomáticos y referentes políticos españoles desde 1808.

\section{Bibliografía}

Adelman, J. (2007). Sovereignty and Revolution in the Iberian Atlantic. Princeton: Princeton University Press.

Alexandre, V. (1993). Os sentidos do Império: questão nacional e questão colonial na crise do antigo regime português. Porto: Afrontamento.

Anes, G. (1975). El Antiguo Régimen y los Borbones. Madrid: Alfaguara.

Annino, A. (2008). Imperio, constitución y diversidad en la América Hispana. Historia Mexicana, 229 (1), 179-227. Disponible en: https://doi.org/10.4000/nuevomundo.33052.

— y Ternavasio, M. (2012). Presentación. En A. Annino y M. Ternavasio (coords.). El laboratorio constitucional iberoamericano: 1807/1808-1830 (pp. 9-13). Madrid: Iberoamericana-Estudios AHILA.

Araújo, B. de A. C. (1998). As invasoes francesas e a afirmação das ideas liberáis. En L. Reis Torgal y J. L. Roque (coords.). Historia de Portugal. O Liberalismo (pp. 21-40). Lisboa: Estampa.

Artola Gallego, M. (1978). La España de Fernando VII. Madrid: Espasa-Calpe.

Ávila, A. y Pérez Herrero, P. (2008). Las experiencias de 1808 en iberoamérica. Madrid: Universidad de Alcalá-Universidad Nacional Autónoma de México.

Bély, L. (2002). Casas soberanas y orden político en la Europa de la paz de Utrecht. En P. Fernández Albadalejo (ed.). Los Borbones. Dinastia y memoria de nación en la España del siglo XVIII (pp. 69-96). Madrid: Marcial Pons.

Bonifácio, M. (ed.) (2011). Memorias do Duque Conde Palmela. Lisboa: D. Quixote. 
Brancato, B. (2003). Os Direitos de Carlota Joaquina à Sucessão Espanhola e a Missão Diplomática de Pedro de Sousa Holstein. IV Simpósio Internacional Estados Americanos: Relaçôes Continentais e Intercontinentais (pp. 1-10). Passo Fundo: UPF Editora.

Breña, R. (2006). El primer liberalismo español y los procesos de emancipación de América, 1808-1824. Una revisión historiográfica del liberalismo hispánico. México: Colegio de México.

- (ed.) (2010). En el umbral de las revoluciones hispánicas: el bienio 1808-1810. México: El Colegio de México y Centro de Estudios Políticos y Constitucionales.

Busaall, J. B. (2005). Las instituciones del Reino de Navarra en el debate histórico juridico de la revolución liberal. Pamplona: Universidad Pública de Navarra.

Cardim, P. (2014). Portugal unido y separado. Felipe II, la unión de territorios y el debate sobre la condición politica del reino de Portugal. Valladolid: Universidad de Valladolid.

Chust, M. (coord.) (2007). 1808. La eclosión juntera en el mundo hispano. México: FCE-El Colegio de México.

Costa, D. F. (2013). O Conde de Palmela em Cádis (1810-1812). A crítica das Cortes e a dimensão militar do projeto de candidatura de Carlota de Bourbon a Regência de Espanha. Ler História, 64, 87-110. Disponible en: https://doi.org/10.4000/lerhistoria.248.

Garriga, C. (2009). Un interregno extraordinario: el Reino de la Nueva España en 1808. 20/10 Memoria de las Revoluciones en México, 5, 14-37.

- (dir.) (2010). Historia y constitución: trayectos del constitucionalismo hispano. México: Centro de Investigación y de Docencia Económica.

Gutiérrez, A., Mira, A. y Moreno, M. (coords.) (2014). Presentación Dosier Las reinas y la legitimidad de la monarquía en España, siglos xviı-xx. Historia y Política, 31, 13-19.

Halperin Donghi, T. (1985). Reforma y disolución de los imperios ibéricos, 1750-1850. Madrid: Alianza.

Kantorowicz, E. (2012). Los dos cuerpos del rey. Un estudio de teología politica medieval. Madrid: Akal.

Lima de Oliveira, M. (2006) [1908]. D. Joáo VI no Brasil. Río de Janeiro: Topbooks.

López Cordón, M. V. (2003). La legación española en Lisboa durante el reinado de Fernando VII. Cuadernos de Historia Contemporánea, número extraordinario, 113-126.

- (2009). De infanta ilustrada a princesa política. Carlota Joaquina de Borbón (17851808). En E. de Lorenzo Álvarez (coord.). La época de Carlos IV. Actas del IV Congreso Internacional de la Sociedad Española de Estudios del Siglo XVIII (pp. 731-748). Oviedo: Trea.

- (2014). Reinas madres, Reinas hijas: educación, política y correspondencia en las cortes dieciochescas. Historia y Politica, 31, 49-80.

Lorente, M. y Portillo Valdés, J. (dirs.) (2012). El momento gaditano. La constitución em El orbe hispânico (1808-1826). Madrid: Cortes Generales.

Marques Pereira, S. (1999). D. Carlota Joaquina e os "Espelhos de Clio». Lisboa: Livros Horizonte.

Marçal Lorenço, M. P. (2012). Rainhas no Portugal Moderno. Casa, Corte e Patrimonio. Lisboa: Colibrí. 
Martiré, E. (2006). Carlota Joaquina en las Cortes españolas. En E. Martiré (coord.). La América de Carlos IV, V. 4, Cuadernos de Investigaciones y Documentos (pp. 1-5). Buenos Aires: Instituto de Investigaciones de Historia del Derecho.

- (2008). Carlota Joaquina: infanta, princesa, regente y reina. Actas Congresso das Academias Ibero-Americanas da História. Lisboa: Academia Portuguesa da História.

Moritz Schwarcz, L. (2008). A longa viagem da biblioteca dos reis. Do terremoto de Lisboa á independência do Brasil. San Pablo: Editora Schwarcz.

Nogueira de Azevedo, F. (2002). Carlota Joaquina na corte do Brasil. Río de Janeiro: Civilizaçao Brasileira.

(2008). Carlota Joaquina. Cartas inéditas. Río de Janeiro: Casa da Palabra.

Ozanam, D. (2002). Dinastía, diplomacia y política exterior. En P. Fernández Albadalejo (ed.). Los Borbones: dinastía y memoria de nación en la España del siglo XVIII (pp. 17-46). Madrid: Marcial Pons.

Palacio, G. (2008). Brasil, 1808: una re-invención imperial en los trópicos. En A. Ávila y P. Pérez Herrero (comps.). Las experiencias de 1808 en Iberoamérica (pp. 509-534). Madrid: Universidad de Alcalá-Universidad Nacional Autónoma de México.

Pimenta, J. P. (2011). Estado y Nación en el fin de los imperios ibéricos en el Río de la Plata (1808-1828). Buenos Aires: Sudamericana.

Portillo Valdés, J. M. (2000). Revolución de nación. Origenes de la cultura constitucional en España, 1780-1812. Madrid: Centro de Estudios Políticos y Constitucionales.

- (2006). Crisis Atlántica. Autonomía e independencia en la crisis de la monarquía hispana. Madrid: Marcial Pons.

— (2010). Entre la Historia y la Economía Política. En C. Garriga (dir.). Historia y constitución: trayectos del constitucionalismo hispano (pp. 27-67). México: Centro de Investigación y de Docencia Económica.

Ramos, R. (2008). La «revolución» de 1808 y los orígenes del liberalismo en Portugal: una reinterpretación. En A. Ávila y P. Pérez Herrero (comps.). Las experiencias de 1808 en Iberoamérica (pp. 251-278). Madrid: Universidad de Alcalá-Universidad Nacional Autónoma de México.

Rubio, J. M. (1920). La infanta Carlota Joaquina y la Política de España en América (18081812). Madrid: Imprenta de Estanislao Maestre.

Schultz, K. (2001). Tropical Versailles: empire, monarchy, and the portuguese royal court in Rio de Janeiro, 1808-1821. New York: Routledge.

Serulnikov, S y Lluch, A. (coords.) (2014). Dossier: Latinoamérica y los enfoques globales. Nuevo Mundo Mundos Nuevos. Disponible en: http://nuevomundo.revues.org/66379.

Slemian, A. (2009). Instituciones, legitimidad y [des]orden: crisis de la Monarquía portuguesa y construcción del Imperio de Brasil (1808-1841). En I. Frasquet y A. Slemian (eds.). De las independencias iberoamericanas a los estados nacionales (1810-1850). 200 años de historia (pp. 89-108). Madrid: AHILA-Iberoamericana-Vervuert.

- y Pimenta, J. P. (2008). A corte e o mundo. Uma história do ano em que a família real portuguesa chegou ao Brasil. San Pablo: Alameda.

Struck, B., Ferris, K. y Revel, J. (2011). Introduction: Space and Scale in Transnational History. The International History Review, 33 (4), 573-584. Disponible en: https:/doi.org/ 10.1080/07075332.2011.620735. 
Ternavasio, M. (2013). La princesa negada. Debates y disputas en torno a la Regencia (1808-1810). En V. Hébrard y G. Verdo (eds.). Las independencias hispanoamericanas (pp. 261-275). Madrid: Collection de la Casa de Velázquez.

- (2015). Candidata a la Corona. La infanta Carlota Joaquina en el laberinto de las revoluciones hispanoamericanas. Buenos Aires: Siglo xxI.

Varela Suanzes-Carpegna, J. (2007). El constitucionalismo español y portugués durante la primera mitad del siglo xix. Un estudio comparado. En Álvarez Cuartero et. al. (eds.). Visiones y Revisiones de la Independencia Ibeoramericana (pp. 13-52). Salamanca: Ediciones Universidad de Salamanca.

Werner, M. y Zimmermann, B. (2006). Beyond Comparison: Histoire Croisée and challenge of reflexivity. History and Theory, 45, 30-50. Disponible en: https://doi. $\operatorname{org} / 10.1111 / \mathrm{j} .1468-2303.2006 .00347 . x$. 